\title{
Green Synthesis of Silver Nanoparticles Using Muntingia calabura Leaf Extract and Evaluation of Antibacterial Activities
}

\author{
Mohd Azlan Ahmad 1, Salmiati Salmiati 1,2,*, Marpongahtun Marpongahtun ${ }^{3}$, Mohd Razman Salim ${ }^{4}$, \\ Jumiarti Andi Lolo ${ }^{5}$, Achmad Syafiuddin 1,* (D) \\ 1 Department of Water and Environmental Engineering, Faculty of Engineering, Universiti Teknologi Malaysia, 81310 \\ UTM Johor Bahru, Johor, Malaysia \\ 2 Centre for Environmental Sustainability and Water Security (IPASA), Universiti Teknologi Malaysia, 81310 UTM Johor \\ Bahru, Johor, Malaysia \\ 3 Department of Chemistry, Faculty of Mathematics and Natural Science, Universitas Sumatera Utara, 20155 Medan, \\ Indonesia \\ 4 Department of Civil Engineering, Faculty of Engineering, Technology and Built Environment, UCSI University, 56000 \\ Kuala Lumpur, Malaysia \\ 5 Physics Education, Universitas Kristen Indonesia Toraja, 91811 Tana Toraja, South Sulawesi, Indonesia \\ * Correspondence: salmiati@utm.my (S.S.); ac.syafi@gmail.com (A.S.);
}

Scopus Author ID 55336805500 (S.S.); 56682128000 (A.S.)

Received: 26.04.2020; Revised: 10.05.2020; Accepted: 10.05.2020; Published: 12.05.2020

\begin{abstract}
The present work aims to investigate a green synthesis of AgNPs using Muntingia calabura leaf extract as reducing and stabilizing agents. The AgNPs formation was monitored using UV-Vis spectrophotometer. Characterisations of AgNPs size and shape were observed by TEM. The elemental analysis was analyzed using XDS. The maximum surface Plasmon resonance for AgNPs was detected at $425-430 \mathrm{~nm}$. This study revealed that the AgNPs were polydispersed and polycrystalline nature. The microbial inhibition test against Escherichia coli and Bacillus cereus showed that the muntingia leafmediated AgNPs had inhibited the growth of these bacteria, as indicated by the formation of inhibition zone. The average inhibition zone for Escherichia coli was $10.3 \pm 0.5 \mathrm{~mm}$ and for Bacillus cereus at $9.5 \pm 0.6 \mathrm{~mm}$. TEM results showed that the synthesised AgNPs have spherical form with the sizes ranging from 22 to $37 \mathrm{~nm}$. Hence, the synthesised AgNPs can potentially be applied for water treatment and medicinal purposes.
\end{abstract}

Keywords: Green synthesis; silver nanoparticles; plant extract; antibacterial properties.

(C) 2020 by the authors. This article is an open access article distributed under the terms and conditions of the Creative Commons Attribution (CC BY) license (https://creativecommons.org/licenses/by/4.0/).

\section{Introduction}

The use of silver nanoparticles (AgNPs) in various fields has recently been increasing especially in textiles, medical, and foods because of their attractive features [1-5]. Their antimicrobial properties have been tested against bacteria, viruses, and fungi [6-8]. Nanoparticle synthesis typically uses physical approaches such as thermal decomposition and thermal/laser ablation or by a chemical such as electrochemical precipitation, sol-gel process, and aerosol pyrolysis. Alternatively, it can also be carried out using biological approaches by plants, bacteria, fungi, algae, and yeast. Biological approaches are considered as eco-friendly and economically feasible methods compared to physical and chemical [9].

The physical process involved high energy consumption. In contrast, chemical processes involved toxic chemicals, which can pose unfavourable effects on the environment. 
The minimisation of physical and chemical processes can reduce the cost. Thus, the benefits of using plant extract are because it is cleaner and it provides accessible, safe and non-toxic compounds [10]. Previous studies on plant extract include cashew tree (Anacardium occidentale) gum [11], purple heart plant (Tradescantia pallida)[12], cinnamon (Cinnamomum cassia) [13], sweet pepper (Capsicum frutescence) [14], boldo (Peumus boldus) [15], clammy cherry (Cordia obliqua Willd) [16], and kerson (Muntingia calabura) [17].

Muntingia calabura, is commonly called as pokok ceri or kerukup siam and can be found in Malaysia. It is a fast-growing tree that is wildly grown in the Southern and Northern America and South East Asia [18]. It is traditionally used as a folk remedy for the treatment of fever, incipient cold, liver disease, and antiseptic agent in Southeast Asia [19]. However, the effectiveness of the use of these plant extracts as reducing and stabilizing agents has not been investigated.

In closing the research gap, this study was aimed to investigate the green synthesis of AgNPs using aqueous Muntingia calabura leaf extract as reducing and stabilising agents. Investigation on its bio-reduction reaction was conducted by using UV-Visible spectroscopy technique. The synthesized AgNPs were successfully characterised using FTIR, SEM, HRTEM, and XDS. In the application, antibacterial activities of AgNPs were tested against Gram-positive and Gram-negative bacteria.

\section{Materials and Methods}

\subsection{Materials.}

Silver nitrate $\left(\mathrm{AgNO}_{3}\right)$, nutrient agar, Luria Bertani (LB) broth, and Whatman No.1 filter paper were acquired and used for experimental analysis. Two bacteria, Escherichia coli (E. coli) and Bacillus cereus (B. cereus) were obtained from the Faculty of Biomedical and Engineering (FBME), UTM. Both bacteria were maintained in nutrient agar media and Luria Bertani (LB) broth.

\subsection{Muntingia calabura leaf extract preparation.}

The fresh leaf of Mutinga calabura (M. calabura) was obtained to biosynthesize the silver nanoparticles. The preparation of leaf extract was adapted from previous studies with a little modification [20,21]. Fresh leaves of $M$. calabura were collected and washed thoroughly using tap water twice and by deionized water to remove dirt and debris. The cleaned leaves were dried under the shed and finely cut using a clean scissor. Twenty (20) grams of the leaf was added into $500 \mathrm{~mL}$ of deionized water and heated at $60{ }^{\circ} \mathrm{C}$ for $30 \mathrm{~min}$. This was followed by cooling at room temperature. It was further filtered through Whatman No. 1 filter paper using vacuum filtration system. The filtered leaf extract was stored at $4{ }^{\circ} \mathrm{C}$ for further analysis.

\subsection{Synthesis of AgNPs.}

In the biosynthesis process of AgNPs, the effects of the quantity of fruit extract and concentration of $\mathrm{AgNO}_{3}$ were assessed to intensify the synthesis route in producing the metal nanoparticles. The aqueous solution of $\mathrm{AgNO}_{3}(0.01-0.03 \mathrm{M})$ was used and the volume of the aqueous fruit extract was added at 1:1 ratio $(\mathrm{v} / \mathrm{v})$. The mixture was left under dark condition with stirring using magnetic stirrer for $24 \mathrm{~h}$. As a comparison to show that the AgNPs synthesis was mediated by phytochemicals of $M$. calabura leaf extract, a control flask containing 
aqueous solution of $\mathrm{AgNO}_{3}$ and deionized water was also used and kept under the same condition as the AgNPs synthesizing mixture. The occurrence of silver ions reduction was observed when the mixture optical colour changed from clear brown to dark brown solution. The optical density developments were monitored and measured timely for $1 \mathrm{~h}$ and up to $48 \mathrm{~h}$ using spectrophotometer (Macherey-Nagel Nanocolor UV/Vis).

\subsection{AgNPs characterization.}

Biosynthesized AgNPs consequent of reduction of silver metal ions with aqueous $M$. calabura leaf extract was observed by a spectrophotometer (Macherey-Nagel Nanocolor $\mathrm{UV} / \mathrm{Vis}$ ) it was operated at $1 \mathrm{~nm}$ resolution and wavelength of 200-800 $\mathrm{nm}$. In addition, Energy dispersive spectroscopy (EDS, Oxford Instruments, Oxford, United Kingdom) confirmed the presence of AgNPs elements at $20 \mathrm{keV}$. Moreover, the morphology of AgNPs was structurally characterized in high resolution mode (HR-TEM) using JEOL-ARM200F model instrument. The FTIR analysis was also performed to determine the presence of possible compounds that act as capping and stabilizing agents for the AgNPs in the range from 400 to $4000 \mathrm{~cm}^{-1}$. The analysis was performed using FTIR spectrometer (PerkinElmer Frontier-GPOB model 96046).

\subsection{Antibacterial activity of AgNPs.}

The antibacterial activity of the biosynthesized AgNPs was evaluated against $E$. coli and $B$. cereus by paper disc (6 mm diameter) method adopted from [1]. An overnight grown of E. coli and B. cereus culture (optical density $(\mathrm{OD} 600 \mathrm{~nm}) \approx 0.8 @$ approximately $1 \times 10^{8}$ $\mathrm{CFU} / \mathrm{mL}$ was used. Five millilitres $(5 \mathrm{~mL})$ of bacterial culture was spreaded over MuellerHinton agar plate. Paper discs were prepared by soaking it in respective AgNPs labelled as $0.01 \mathrm{M}, 0.02 \mathrm{M}, 0.03 \mathrm{M}, 9: 1$ and 1:9. The paper discs were air dried under laminar flow then transferred onto the prepared agar plates. Blank paper discs were soaked in filter sterilized deionized water. The plates were incubated at $30{ }^{\circ} \mathrm{C}$ for $24 \mathrm{~h}$. Each bacterial plate was made in triplicates. The antibacterial activity was determined by averaging the diameter of the inhibition zone observed around respective paper discs.

\section{Results and Discussion}

\subsection{UV-Vis spectroscopy of AgNPs.}

The reaction of leaf extract with $\mathrm{AgNO}_{3}$ was performed using different concentrations of $\mathrm{AgNO}_{3} ; 0.01 \mathrm{M}, 0.02 \mathrm{M}, 0.03 \mathrm{M}$, and two ratio of $\mathrm{AgNO} 3(0.01 \mathrm{M})$ and extract which were 9:1 and 1:9. Figure 1 represents the rapid UV spectrum of AgNPs development when using $\mathrm{AgNO}_{3}$. After $1 \mathrm{~h}$, rapid change of colour was clearly observed from colourless to dark brown as seen in Figure 1 (f). The AgNPs synthesis was confirmed by the UV-Vis spectrum of surface plasmon resonance (SPR) at $425-430 \mathrm{~nm}$ of adsorption band. It was noticed that at each condition, the longer the incubation time, the higher the UV-Vis wavelength adsorption but with different intensity. Steady development of AgNPs was indicated by the straight line of increment $\lambda_{\max }$ as shown in Figure 1.

Narrow SPR peak at $425-430 \mathrm{~nm}$ was observed at $0.02 \mathrm{M}$ of $\mathrm{AgNO}_{3}$ with highest $\lambda_{\max }$ of 0.991 as depicted in Figure 1. The absorbance intensity showed a significant decrease when the reaction is performed at a concentration of 0.01 and $0.03 \mathrm{M}$ as well as 9:1 and 1:9 (v/v). This was due to agglomeration which was faster at concentration of $0.01 \mathrm{M}$ and $0.03 \mathrm{M}$ making 
the SPR shifts and broadening the wavelength. This indicated that particle formation was influenced by the concentration of precursor and the size, shape and surrounding medium. This is referred to as the phytochemical compounds in the leaf extract [22] and [17].
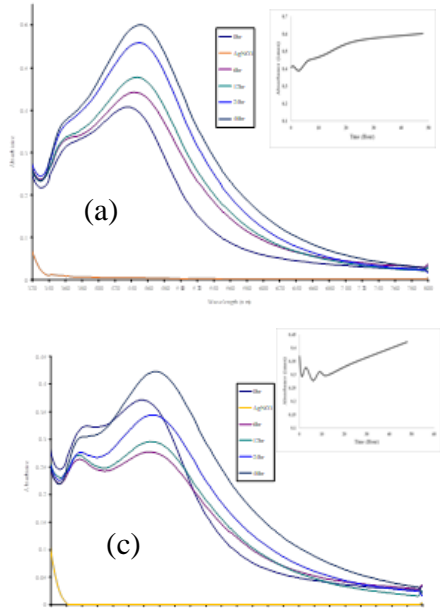

(c)

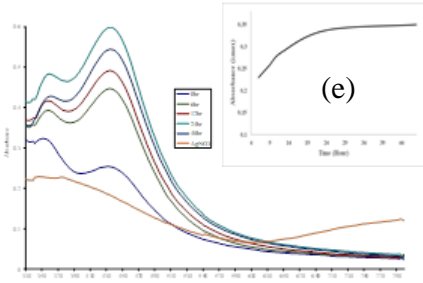

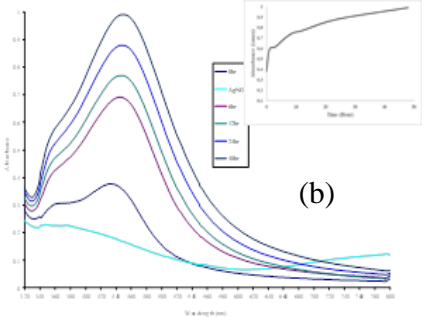
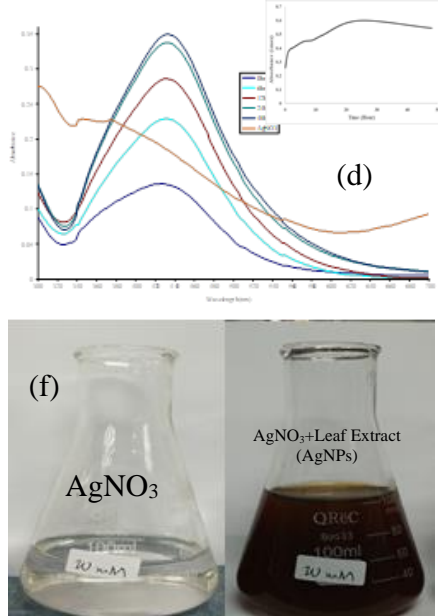

Figure 1. UV-Vis spectra of AgNPs at (a) $0.01 \mathrm{M}$, (b) $0.02 \mathrm{M}$, (c) $0.03 \mathrm{M}$, (d) leaf extract: $0.01 \mathrm{M} \mathrm{AgNO}_{3}$ ratio 9:1 and (e) leaf extract: $0.01 \mathrm{M} \mathrm{AgNO}_{3}$ ratio 1:9 as well as (f) the colour changes of $\mathrm{AgNO}_{3}$ solution after leaf extract addition.

\subsection{FTIR analysis.}

The FTIR was performed to identify functional groups that exist in the leaf extract of M. calabura and on the surface of AgNPs synthesized using the extract. These functional groups are responsible for the reduction of $\mathrm{AgNO}_{3}$ to $\mathrm{Ag}^{0}$, capping and stabilization of silver nanoparticles in the solution. Figure 2 shows the FTIR spectrum of $M$. calabura leaf extract (b) and its AgNPs (a). The infra-red (IR) bands of $3307.92 \mathrm{~cm}^{-1}$ are characterized as -OH, $\mathrm{NH},-\mathrm{CH}$ of alcohol, aliphatic primary amine and alkyne. The band of $1637.56 \mathrm{~cm}^{-1}$ indicated $-\mathrm{C}=\mathrm{C}$ and $-\mathrm{NH}_{2}$ of amide and amine group, mainly from protein compound. The compounds contained in the leaf extract are flavonoid, polyphenol and terpenoid [17]. A systematic literature study by [23] on $M$. calabura possesses a high content of antioxidant phytochemicals including terpenoids, flavonoids, tannins, and phenols which are beneficial for pharmacological activities. These compounds act as reducing agents. Meanwhile, the IR spectrum for AgNPs shows that the IR band of $2355.08 \mathrm{~cm}^{-1}$ was absent. The band supposedly of $-\mathrm{C} \equiv \mathrm{N}$ (nitriles group) and $\mathrm{P}-\mathrm{H}$ ester stretching. This suggests that the functional groups are responsible for stabilizing and capping the AgNPs. It is further suggested that the protein structures in $M$. calabura extract are intact due to interaction with $\mathrm{Ag}^{+}$ions or nanoparticles [24]. The IR bands in $619-542 \mathrm{~cm}^{-1}$ correspond to S-S and C-S stretching.

Interestingly, many previous researchers highlighted the significant antioxidant activity played by terpenoids. Quercetin in Tulsi plant extract (Ocimum sanctum) as one type of terpenoid [25], was reported as the main compound reacting with $\mathrm{Ag}^{+}$ion in synthesizing AgNPs. The terpenoids in geranium leaves were reported as the active compound in reducing the silver ions to AgNPs [26]. 

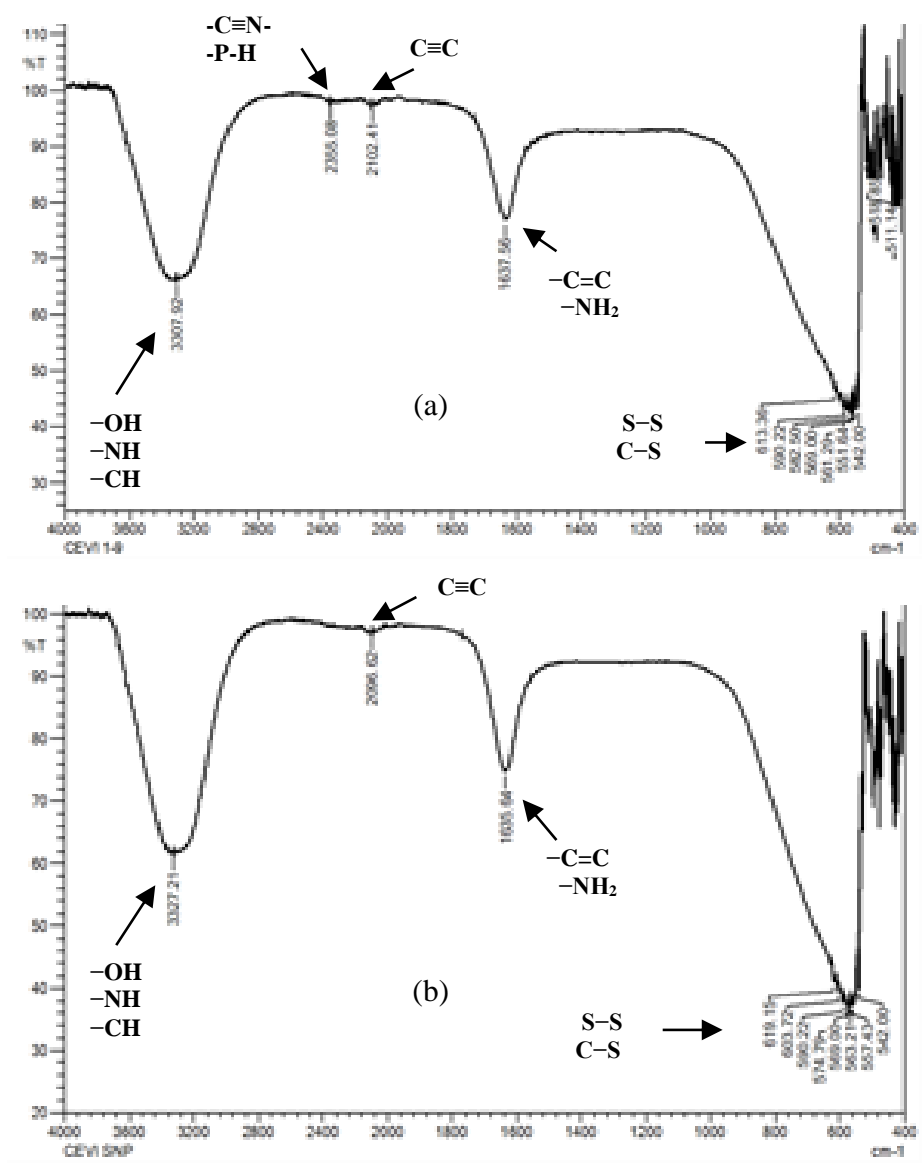

Figure 2. FTIR spectra of (a) Muntingia calabura leaf extract and (b) AgNPs.

\subsection{Morphology, size, and EDS analyses.}

The surface morphology and size of AgNPs provided by SEM image showed that the AgNPs synthesized with diameter ranged from 30-60 nm in size. The AgNPs were scattered evenly as indicated by Figure 3. The large distribution of AgNPs diameter size was as a result of various phytochemical compounds in $M$. calabura leaf extract that act as reducing and capping agents [17].

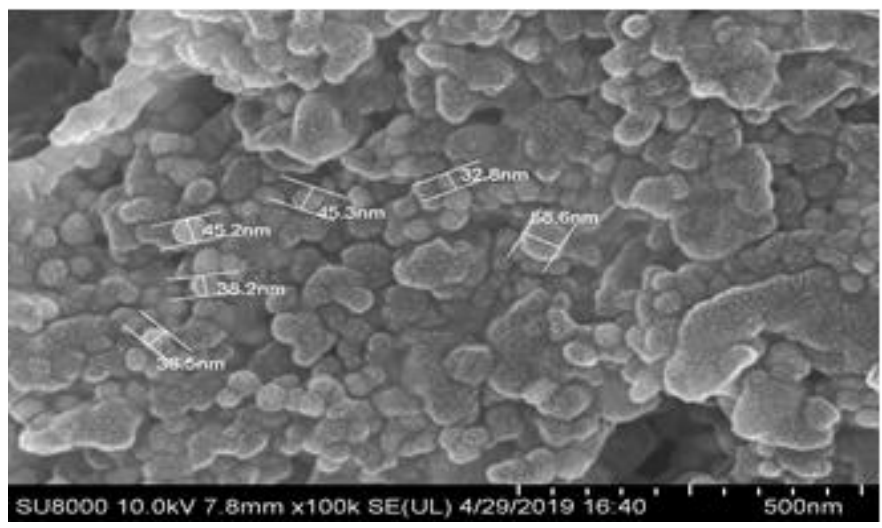

Figure 3. SEM image of synthesized AgNPs at $10 \mathrm{kV}$ at $100000 \times$ magnification.

TEM images which clearly show that the synthesized AgNPs were poly-dispersed in spherical shapes (Figure 4(a)). The diameter length or size distribution ranged from 7 to $52 \mathrm{~nm}$ (Figure 4(b)). The high frequency of size was within 22 to $37 \mathrm{~nm}$. The EDX instrument further confirmed the Ag element in the synthesized AgNPs. This elemental analysis also confirmed the existence of other elements such as $\mathrm{C}, \mathrm{O}$, and $\mathrm{P}$ that are determined and shown in functional 
groups from previous FTIR analysis. Thus, it proved that the AgNPs can be successfully synthesized using the $M$. calabura leaf extract and the AgNPs have been capped or encapsulated with various phytochemicals contributed by the $M$. calabura leaf extract. The inset SAED image of TEM of nanoparticles is presented in Figure 4(a). Bright diffraction spots in each image indicated that the silver nanoparticles are of single crystal quality [27], with polycrystalline nature [28].

(a)

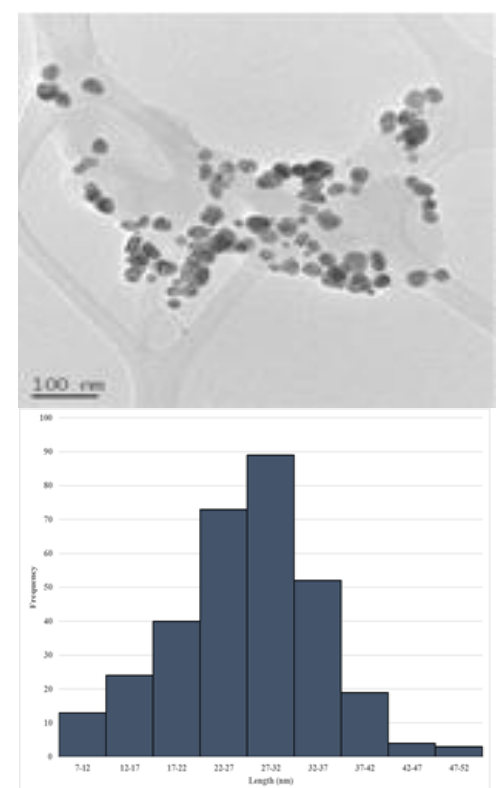

Figure 4. (a) TEM images of AgNPs mediated by M. calabura leaf extract and (b) AgNPs size distribution.

Further confirmation on the elements which exist in the AgNPs was conducted. It was based on the EDS spectrum it is confirmed the Ag element that existed in the synthesized AgNPs. Other significant elements that co-existed are C, O, P and S as shown in Figure 5. All these elements were determined and shown in functional groups from previous FTIR analysis (Figure 2). This indicated that the AgNPs were well capped/encapsulated with various phytocompounds originated from the $M$. calabura leaf extract.

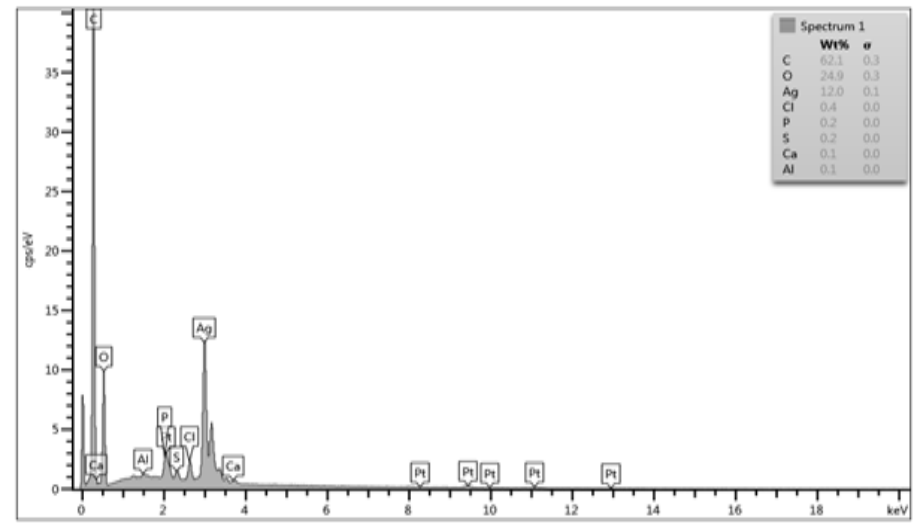

Figure 5. EDS sepctra of the synthesized AgNPs.

\subsection{Possible mechanism of AgNPs synthesis.}

Currently, there is a clear explanation on reduction of silver ions into AgNPs by phytocompounds, flavonoid, polyphenol and terpenoid in plant extract [17]. These compounds act as reducing and capping agents [29]. The $-\mathrm{OH}$ functional groups as depicted in Figure 6 
reacted with $\mathrm{Ag}^{+}$and reduced it into AgNPs. Figure 6 demonstrated the generation of two proton i.e., a quercetin molecule for the reduction of $\mathrm{Ag}$ ions via reduction-oxidation reaction.

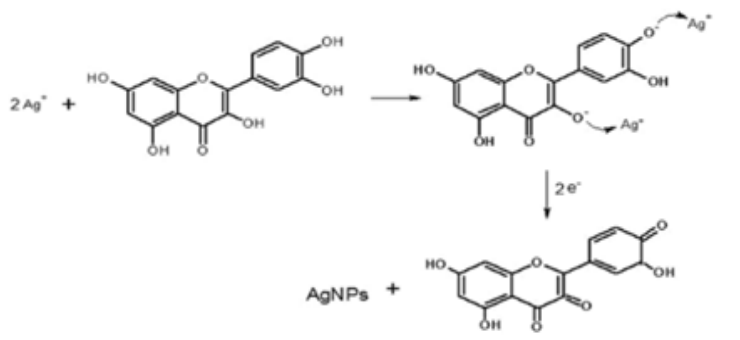

Figure 6. Silver ions reduction by terpenoid (quercetin) molecule adapted from [25].

\subsection{Antibacterial activity of AgNPs.}

Based on the antibacterial activity, AgNPs synthesized from $0.02 \mathrm{M} \mathrm{AgNO}_{3}$ showed a better inhibition activity against both $E$. coli and B. cereus compared to other concentrations of $\mathrm{AgNO}_{3}$ as shown in Table 1 and Figure 7. There is significantly different in bacterial inhibition efficiency between AgNPs from 0.02 M and other concentrations. For example, in E. coli inhibition, $\mathrm{AgNPs}$ from $0.01 \mathrm{M} \mathrm{AgNO}_{3}$ was inefficient by $17 \%$ and $10 \%$ from $0.03 \mathrm{M} \mathrm{AgNO}_{3}$. Growth inhibition by AgNPs from different mixture ratio of leaf extract and $0.01 \mathrm{M} \mathrm{AgNO}_{3}$ was lower than the pure concentration of $\mathrm{AgNO}_{3}$. This was due to the fact that the leaf extract at $90 \%$ was not able to act as antibacterial agent. The leaf extract at $10 \%$ volume synthesized lower intensity of AgNPs which is insufficient to suppress the growth of bacteria. The AgNPs killing mechanism is still specifically uncertain. However, there are research findings which highlighted that bacterial cell membrane interacts with AgNPs due to the existence of S and P constituent. Subsequently, this interaction can initiate the killing by interrupting the bacteria cell division and respiratory chain [30].

Table 1. Zone of inhibition of AgNPs by M. calabura leaf extract.

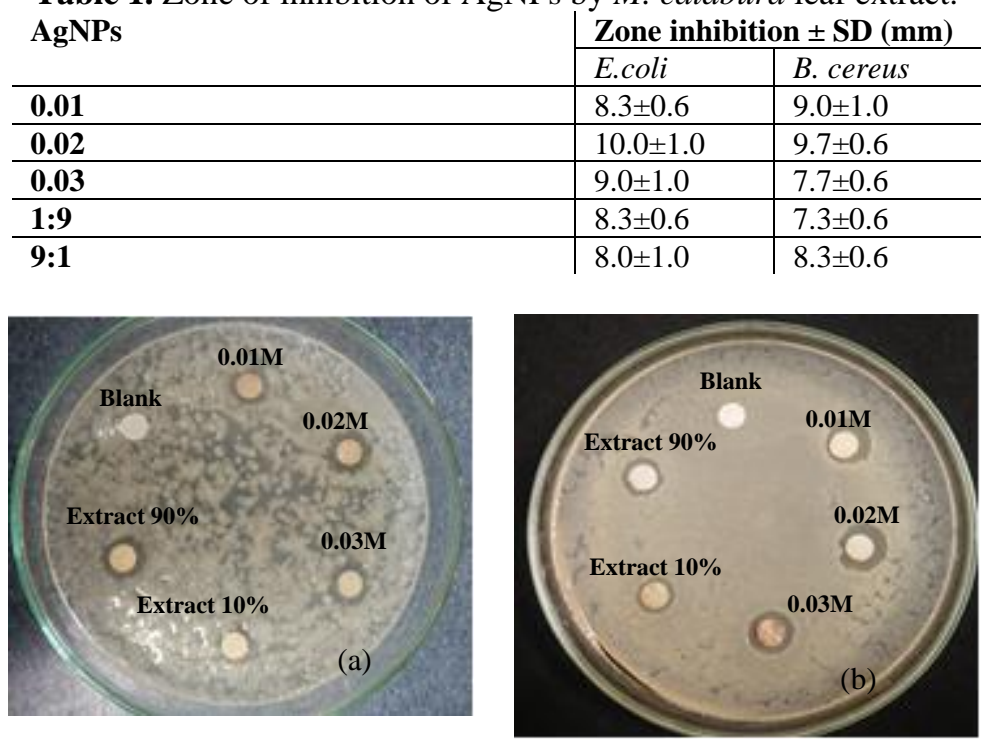

Figure 7. Zone of inhibition of AgNPs against (a) B.cereus and (b) E. coli.

\section{Conclusions}

The aim of this study was to investigate the green synthesis of AgNPs using aqueous Muntingia calabura leaf extract as reducing and stabilising agents. The FTIR analysis revealed that the phytocompounds in M. calabura are flavonoid, polyphenol, and terpenoid. The 
morphological observation confirmed the poly-dispersed spherical shape and size ranging from 22 to $37 \mathrm{~nm}$. The polycrystalline nature of the synthesized AgNPs was confirmed by the TEM analysis. The AgNPs synthesized using $0.02 \mathrm{M} \mathrm{AgNO}_{3}$ were the most efficient in inhibiting all bacterial growth. In general, findings from this work confirmed that the $M$. calabura leaf extract has the potential as the biological alternative for AgNPs production.

\section{Funding}

This study was funded by the Ministry of Education Malaysia, grant number R.J130000.7851.5F095 and the Universiti Teknologi Malaysia under GUP grant, grant number Q.J130000.2522.18H92.

\section{Acknowledgments}

The authors thank the Centre for Environmental Sustainability and Water Security for facilitating this study.

\section{Conflicts of Interest}

The authors declare no conflict of interest.

\section{References}

1. Nurul Aini, A.; Al Farraj, D.A.; Endarko, E.; Rubiyanto, A.; Nur, H.; Al Khulaifi, M.M.; Hadibarata, T.; Syafiuddin, A. A new green method for the synthesis of silver nanoparticles and their antibacterial activities against gram-positive and gram-negative bacteria. Journal of the Chinese Chemical Society 2019, 66, 705712, https://doi.org/10.1002/jccs.201800412.

2. Syafiuddin, A.; Salmiati, S.; Salim, M.R.; Kueh, A.B.H.; Hadibarata, T.; Nur, H. A review of silver nanoparticles: research trends, global consumption, synthesis, properties, and future challenges. Journal of the Chinese Chemical Society 2017, 64, 732-756, https://doi.org/10.1002/jccs.201700067.

3. Syafiuddin, A. Toward a comprehensive understanding of textiles functionalized with silver nanoparticles. Journal of the Chinese Chemical Society 2019, 66, 793-814, https://doi.org/10.1002/jccs.201800474.

4. Shaligram, N.S.; Bule, M.; Bhambure, R.; Singhal, R.S.; Singh, S.K.; Szakacs, G.; Pandey, A. Biosynthesis of silver nanoparticles using aqueous extract from the compactin producing fungal strain. Process Biochemistry 2009, 44, 939-943, http://dx.doi.org/10.1016/j.procbio.2009.04.009.

5. Gopinath, V.; MubarakAli, D.; Priyadarshini, S.; Priyadharsshini, N.M.; Thajuddin, N.; Velusamy, P. Biosynthesis of silver nanoparticles from tribulus terrestris and its antimicrobial activity: a novel biological approach. Colloids and Surfaces B: Biointerfaces 2012, 96, 69-74, https://doi.org/10.1016/j.colsurfb.2012.03.023.

6. Rolim, W.R.; Pelegrino, M.T.; de Araújo Lima, B.; Ferraz, L.S.; Costa, F.N.; Bernardes, J.S.; Rodigues, T.; Brocchi, M.; Seabra, A.B. Green tea extract mediated biogenic synthesis of silver nanoparticles: Characterization, cytotoxicity evaluation and antibacterial activity. Applied Surface Science 2019, 463, 6674, https://doi.org/10.1016/j.apsusc.2018.08.203.

7. Syafiuddin, A.; Salmiati, S.; Hadibarata, T.; Kueh, A.B.H.; Salim, M.R. Novel weed-extracted silver nanoparticles and their antibacterial appraisal against a rare bacterium from river and sewage treatment plan. Nanomaterials 2018, 8, 1-17, https://doi.org/10.3390/nano8010009.

8. Syafiuddin, A.; Salmiati, S.; Hadibarata, T.; Salim, M.R.; Kueh, A.B.H.; Sari, A.A. A purely green synthesis of silver nanoparticles using Carica papaya, Manihot esculenta, and Morinda citrifolia: Synthesis and antibacterial evaluations. Bioprocess and Biosystems Engineering 2017, 40, 1349-1361, https://doi.org/10.1007/s00449-017-1793-z.

9. Anbu, P.; Gopinath, S.C.B.; Yun, H.S.; Lee, C.G. Temperature-dependent green biosynthesis and characterization of silver nanoparticles using balloon flower plants and their antibacterial potential. Journal of Molecular Structure 2019, 1177, 302-309, https://doi.org/10.1016/j.molstruc.2018.09.075.

10. Behravan, M.; Hossein Panahi, A.; Naghizadeh, A.; Ziaee, M.; Mahdavi, R.; Mirzapour, A. Facile green synthesis of silver nanoparticles using Berberis vulgaris leaf and root aqueous extract and its antibacterial activity. International Journal of Biological Macromolecules 2019, 124, 148-154, https://doi.org/10.1016/j.ijbiomac.2018.11.101.

11. Araruna, F.B.; de Oliveira, T.M.; Quelemes, P.V.; de Araújo Nobre, A.R.; Plácido, A.; Vasconcelos, A.G.; de Paula, R.C.M.; Mafud, A.C.; de Almeida, M.P.; Delerue-Matos, C.; Mascarenhas, Y.P.; Eaton, P.; de Souza de Almeida Leite, J.R.; da Silva, D.A. Antibacterial application of natural and carboxymethylated 
cashew gum-based silver nanoparticles produced by microwave-assisted synthesis. Carbohydrate Polymers, 2019 https://doi.org/10.1016/j.carbpol.2019.115260.

12. Hasnain, M.S.; Javed, M.N.; Alam, M.S.; Rishishwar, P.; Rishishwar, S.; Ali, S.; Nayak, A.K.; Beg, S. Purple heart plant leaves extract-mediated silver nanoparticle synthesis: Optimization by Box-Behnken design. Materials Science \& Engineering. C: Materials for Biological Applications 2019, 99, 1105-1114, https://doi.org/10.1016/j.msec.2019.02.061.

13. Premkumar, J.; Sudhakar, T.; Dhakal, A.; Shrestha, J.B.; Krishnakumar, S.; Balashanmugam, P. Synthesis of silver nanoparticles (AgNPs) from cinnamon against bacterial pathogens. Biocatalysis and Agricultural Biotechnology 2018, 15, 311-316, https://doi.org/10.1016/j.bcab.2018.06.005.

14. Shankar, T.; Karthiga, P.; Swarnalatha, K.; Rajkumar, K. Green synthesis of silver nanoparticles using Capsicum frutescence and its intensified activity against E. coli. Resource-Efficient Technologies 2017, 3, 303-308, https://doi.org/10.1016/j.reffit.2017.01.004.

15. Sánchez, G.R.; Castilla, C.L.; Gómez, N.B.; García, A.; Marcos, R.; Carmona, E.R. Leaf extract from the endemic plant Peumus boldus as an effective bioproduct for the green synthesis of silver nanoparticles. Materials Letters 2016, 183, 255-260, https://doi.org/10.1016/j.matlet.2016.07.115.

16. Saidu, F.K.; Mathew, A.; Parveen, A.; Valiyathra, V.; Thomas, G.V. Novel green synthesis of silver nanoparticles using clammy cherry (Cordia obliqua Willd) fruit extract and investigation on its catalytic and antimicrobial properties. SN Applied Sciences 2019, 1, https://doi.org/10.1007/s42452-019-1302-X.

17. Wahid Wahab, A.; Karim, A.; Asmawati, A.; Wayan Sutapa, I. Bio-synthesis of gold nanoparticles through bioreduction using the aqueous extract of Muntingia calabura L. leaf. Oriental Journal of Chemistry 2018, 34, 401-409, https://doi.org/10.13005/ojc/340143.

18. Mounika, B.; Sarojini, S. Muntingia calabura (Jamaica cherry): an overview. PharmaTutor 2018, 6, https://doi.org/10.29161/PT.v6.i11.2018.1.

19. Sufian, A.S.; Ramasamy, K.; Ahmat, N.; Zakaria, Z.A.; Yusof, M.I. Isolation and identification of antibacterial and cytotoxic compounds from the leaves of Muntingia calabura L. Journal Ethnopharmacology 2013, 146, 198-204, https://doi.org/10.1016/j.jep.2012.12.032.

20. Syafiuddin, A.; Salmiati, S.; Hadibarata, T.; Kueh, A.B.H.; Salim, M.R.; Zaini, M.A.A. Silver nanoparticles in the water environment in Malaysia: Inspection, characterization, removal, modeling, and future perspective. Scientific Reports 2018, 8, 1-15, https://doi.org/10.1038/s41598-018-19375-1.

21. Syafiuddin, A.; Salmiati, S.; Hadibarata, T.; Salim, M.R.; Kueh, A.B.H.; Suhartono, S. Removal of silver nanoparticles from water environment: Experimental, mathematical formulation, and cost analysis. Water, Air, and Soil Pollution 2019, 230, 102-117, https://doi.org/10.1007/s11270-019-4143-8.

22. Desai, R.; Mankad, V.; Gupta, S.; Jha, P. size distribution of silver nanoparticles: uv-visible spectroscopic assessment. Nanoscience and Nanotechnology Letters 2012, 4, 30-34, https://doi.org/10.1166/nnl.2012.1278.

23. Mahmood, N.D.; Nasir, N.L.; Rofiee, M.S.; Tohid, S.F.; Ching, S.M.; Teh, L.K.; Salleh, M.Z.; Zakaria, Z.A. Muntingia calabura: a review of its traditional uses, chemical properties, and pharmacological observations. Pharmaceutical Biology 2014, 52, 1598-623, https://doi.org/10.3109/13880209.2014.908397.

24. Jyoti, K.; Baunthiyal, M.; Singh, A. Characterization of silver nanoparticles synthesized using Urtica dioica Linn. leaves and their synergistic effects with antibiotics. Journal of Radiation Research and Applied Sciences 2019, 9, 217-227, https://doi.org/10.1016/j.jrras.2015.10.002.

25. Jain, S.; Mehata, M.S. Medicinal Plant Leaf Extract and Pure Flavonoid Mediated Green Synthesis of Silver Nanoparticles and their Enhanced Antibacterial Property. Sci Rep 2017, 7, https://doi.org/10.1038/s41598017-15724-8.

26. Shankar, S.S.; Ahmad, A.; Pasricha, R.; Sastry, M. Bioreduction of chloroaurate ions by geranium leaves and its endophytic fungus yields gold nanoparticles of different shapes. Journal of Materials Chemistry 2003, 13, https://doi.org/10.1039/b303808b.

27. Li, S.; Shen, Y.; Xie, A.; Yu, X.; Qiu, L.; Zhang, L.; Zhang, Q. Green synthesis of silver nanoparticles using Capsicum annuum L. extract. Green Chemistry 2007, 9, 852-858, https://doi.org/10.1039/B615357G.

28. Kishore, M.; Hanumantha Rao, Y. Green synthesis and characterization of silver nanoparticle from ampelocissus latifolia root extract. Materials Today: Proceedings 2018, 5, 26271-26279, https://doi.org/10.1016/j.matpr.2018.08.077.

29. Dauthal, P.; Mukhopadhyay, M. Noble metal nanoparticles: plant-mediated synthesis, mechanistic aspects of synthesis, and applications. Industrial \& Engineering Chemistry Research 2016, 55, 9557-9577, https://doi.org/10.1021/acs.iecr.6b00861.

30. Rai, M.; Yadav, A.; Gade, A. Silver nanoparticles as a new generation of antimicrobials. Biotechnology Advances 2009, 27, 76-83, https://doi.org/10.1016/j.biotechadv.2008.09.002. 